\title{
Cross-sectional assessments of participants' characteristics and loss to follow-up in the first Opioid Substitution Therapy Pilot Program in Kabul, Afghanistan
}

Horacio Ruiseñor-Escudero ${ }^{1,2^{*}}$ (D) Alexander Vu ${ }^{2,3}$, Andrea L Wirtz ${ }^{4}$, Itziar Familiar-Lopez ${ }^{1}$, Mark Berry ${ }^{5}$, Iliassou Mfochive ${ }^{2}$, Cyrus Engineer ${ }^{2,9}$, Ahmad Farhad ${ }^{6}$, Senop Tschakarjan ${ }^{6}$, Ernst Wisse ${ }^{6,7}$, Feda M Paikan ${ }^{8}$ and Gilbert Burnham²

\begin{abstract}
Background: Kabul has over 12,000 people who inject drugs (PWID), most of them heroin users, and opioid substitution therapy has recently been introduced as an effective method to reduce opioid use. We aimed to evaluate a pilot Opioid Substitution Therapy Pilot Program (OSTPP) in Kabul, Afghanistan, particularly to (1) describe characteristics of the participants enrolled in the program and (2) identify factors associated with client retention in the OSTPP.

Findings: Two cross-sectional surveys evaluated participants attending the OSTPP at baseline $(n=83)$ and 18 months after $(n=57)$. Questionnaires assessed socio-demographic, drug use behavior, and general and mental health factors. After 18 months, 57 participants remained in the OSTPP. Participants lost to follow-up were younger $(p<0.01)$ and married $(p<0.01)$ and had no family contact $(p<0.01)$. Participants at 18 months reported no criminal activity in the last month and only two (3.5\%) reported heroin use in the last month, constituting significant decreases from baseline.
\end{abstract}

Conclusions: While preliminary results are promising, further evaluation is needed to determine the feasibility of implementing OSTPP in this setting and effectiveness in reducing injection risk behaviors in Afghanistan.

Keywords: Opiate substitution therapy, Heroin, Methadone, Injecting drug use, Afghanistan

\section{Introduction}

In 2012, it was estimated that over 12,000 PWID were living in Kabul alone [1]. Between 2008 and 2011, Afghanistan was one of only five countries in the world to report an increase in the prevalence of injecting drug use [2], likely attributable to broad structural factors including poor socioeconomic conditions, the increasing number of returning refugees, high-opium production, and new trafficking routes [3, 4]. As elsewhere, in Afghanistan, injecting drug use has been associated with

\footnotetext{
*Correspondence: ruiseore@msu.edu

'Department of Psychiatry, Michigan State University, College of

Ostheopathic Medicine, 965 E Fee Hall Suite A227, Lansing, MI 48824, USA

${ }^{2}$ Department of International Health, Johns Hopkins Bloomberg School of

Public Health, 615 N Wolfe Street, Baltimore, MD 21205, USA

Full list of author information is available at the end of the article
}

hepatitis $\mathrm{C}$ virus (HCV) and HIV transmission $[5,6]$ and with substantial social implications, such as loss of employment and productivity [7].

Opioid substitution therapy (OST) is an evidence-based pharmacological intervention to treat opioid dependence [8]. OST replaces the use of illicit opiates, indirectly reduces injecting frequency, and improves health and social outcomes and evidence further suggests that OST may reduce HIV incidence $[9,10]$.

In February 2010, Medecins du Monde (MdM), with support from the Afghan Ministry of Public Health $(\mathrm{MoPH})$ and the World Bank, implemented the first OST pilot program (OSTPP) in Kabul, Afghanistan. In 2012, the Johns Hopkins University (JHU) evaluated the OSTPP in collaboration with MdM and the Afghan 


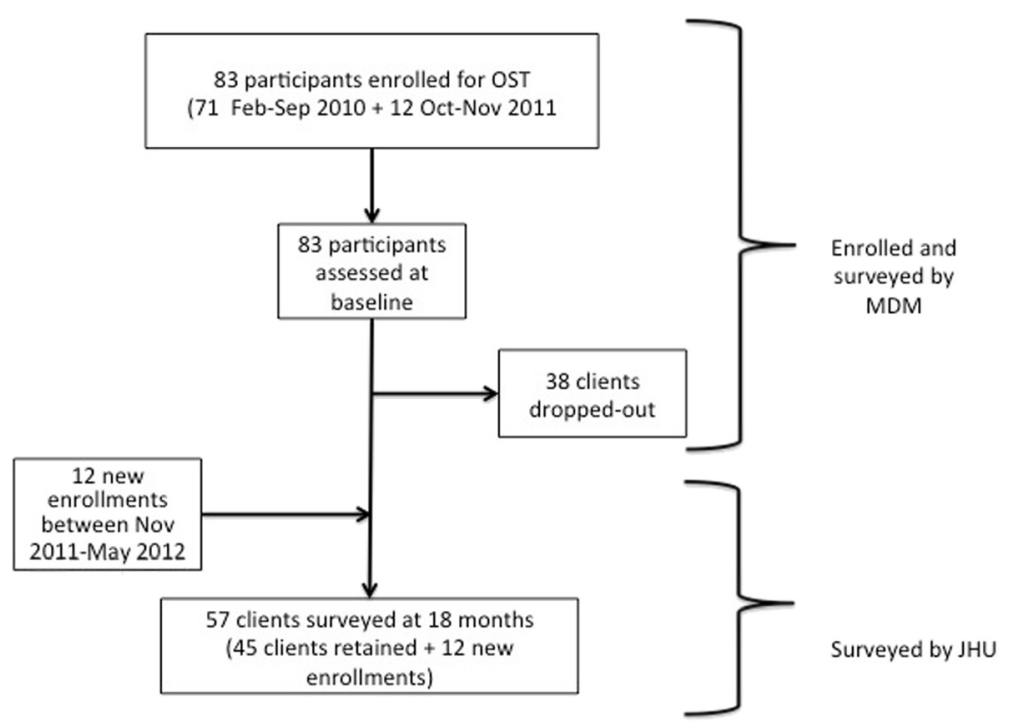

Fig. 1 Participants enrolled and surveyed in the OSTPP between February 2010 and May 2012. Eighty-three participants were initially enrolled and surveyed by MdM, 38 dropped-out, and 45 were retained. After 18 months, 57 clients were surveyed by JHU

National AIDS Control Program (NACP). This analysis aimed to (1) describe the characteristics of the participants enrolled in the program and (2) identify factors associated with client retention.

\section{Methods}

\section{Setting and participants}

The OSTPP clinic was located in central Kabul. Daily clinical visits were required of participants for daily methadone dosing. Ancillary services included psychosocial therapy, basic medical services, recreational activities, and educational programs. MdM enrolled active injecting drug users giving priority to those with poorer medical assessments. Participants were invited by MdM's out-reach services to enroll into the OSTPP. Edibility criteria for baseline included providing consent and currently injecting heroin and for endline assessment included being an enrolled participant of the OSTPP, male, $\geq 18$ years, and providing verbal informed consent.

\section{Data collection and procedures}

Data are derived from two cross-sectional surveys conducted at enrollment (baseline) and at endline, 18 months later. After completing the verbal informed consent process, participants at baseline assessment and endline were surveyed using a structured, interviewer-administered questionnaire that included socio-demographic characteristics, injecting behaviors, criminal history, social integration, and general and mental health topics. Data were collected by trained MdM interviewers at baseline and by trained JHU interviewers at endline. All questions were developed in English, translated into Dari, and back- translated by a certified translator. No participation incentive was provided.

The study was approved by the Institutional Review Boards of the Afghan MoPH and Johns Hopkins Bloomberg School of Public Health.

\section{Measures}

Mental health was assessed prior to enrollment by self-report of depressive symptoms using a 10-item measure developed by MdM for patient intake, which included psychotic symptoms (five items) and posttraumatic stress disorder (PTSD) symptoms (five items). Responses to each symptom domain were recorded as "Yes" (present) or "No" (absent) and added to obtain total symptom counts and for each domain, separately. Cronbach's alpha was 0.93. General health status was self-reported using a 10-point Likert scale, with higher scores indicating better selfreported health.

Measures of substance use behaviors included heroin use after enrollment into the OSTPP, frequency of injection in the last month (once a day/daily vs. less than daily for analysis), history of imprisonment, and frequency of contact with family members in the past month and were categorized as binary responses. HIV $1 / 2$ and $\mathrm{HCV}-\mathrm{Ab}$ testing were conducted by MDM using Afghan MoPH guidelines.

\section{Data analysis}

Secondary data analysis was conducted with data from baseline participants and endline participants. MdM collects participant's data anonymously, prohibiting identification of the participants who were later enrolled into 
Table 1 Baseline socio-demographic and drug use characteristics of participants enrolled, lost to follow-up, and retained in the OSTPP in Kabul, Afghanistan

\begin{tabular}{|c|c|c|c|c|}
\hline \multirow[t]{2}{*}{ Characteristic } & $\begin{array}{l}\text { Total baseline participants } \\
(N=83)\end{array}$ & $\begin{array}{l}\text { Lost to follow-up } \\
(N=38)\end{array}$ & $\begin{array}{l}\text { Baseline participants retained by endline } \\
(N=45)\end{array}$ & \multirow[t]{2}{*}{$p$ value } \\
\hline & $n(\%)$ & $n(\%)$ & $n(\%)$ & \\
\hline \multicolumn{5}{|l|}{ Age (years) } \\
\hline $18-24$ & $13(15.7)$ & $11(29.0)$ & $2(4.4)$ & $<0.01$ \\
\hline $25-29$ & $23(27.7)$ & $10(26.3)$ & $13(28.9)$ & 0.77 \\
\hline $30-34$ & $17(20.5)$ & $7(18.4)$ & $10(22.2)$ & 0.51 \\
\hline $35+$ & $30(36.1)$ & $10(26.3)$ & $20(44.4)$ & 0.01 \\
\hline \multicolumn{5}{|l|}{ Marital status ${ }^{a}$} \\
\hline Single & $43(51.8)$ & $14(37.8)$ & $29(64.4)$ & \multirow[t]{2}{*}{$<0.01$} \\
\hline Married/engaged & $37(44.5)$ & $21(56.8)$ & $16(35.6)$ & \\
\hline \multicolumn{5}{|l|}{ Family contact in the past month } \\
\hline No contact & $21(25.3)$ & $16(42.1)$ & $5(11.1)$ & \multirow[t]{3}{*}{$<0.01$} \\
\hline Less than daily & $16(19.3)$ & $7(18.4)$ & $9(20.0)$ & \\
\hline Daily & $46(55.4)$ & $15(39.5)$ & $31(68.9)$ & \\
\hline General health score mean (SD) (range: 1-10) & $5.1(2.1)$ & $5.2(2.4)$ & $5.0(1.8)$ & 0.67 \\
\hline \multicolumn{5}{|l|}{ Mental health symptoms (range: 1-20) } \\
\hline Total number of symptoms, mean (SD) & $6.5(3.7)$ & $6.7(4.4)$ & $6.2(2.9)$ & 0.62 \\
\hline Depressive symptoms mean(SD) & $4.3(2.4)$ & $4.5(2.5)$ & $4.1(2.3)$ & 0.42 \\
\hline PTSD symptoms mean (SD) & $2.7(1.6)$ & $1.2(1.5)$ & $1.5(1.6)$ & 0.34 \\
\hline Psychotic symptoms mean (SD) & $1.5(1.4)$ & $1.3(1.7)$ & $0.38(1.1)$ & $<0.01$ \\
\hline \multicolumn{5}{|l|}{ Frequency of heroin use ${ }^{b}$} \\
\hline Once a week —less than daily & $1(1.2)$ & $1(2.6)$ & $0(0)$ & \multirow[t]{3}{*}{0.05} \\
\hline Daily & 79 (95.2) & $36(94.7)$ & $43(95.6)$ & \\
\hline No response & $3(3.6)$ & $1(2.6)$ & $2(4.4)$ & \\
\hline \multicolumn{5}{|l|}{ Ever injected drugs } \\
\hline Yes (not in the past month) & $34(41.0)$ & $15(39.5)$ & $19(42.2)$ & \multirow[t]{3}{*}{0.67} \\
\hline Yes (past month) & $36(43.4)$ & 15 (38.5) & $21(46.7)$ & \\
\hline No response & $13(15.7)$ & $8(2.2)$ & $5(2.2)$ & \\
\hline Age first heroin use mean (SD) & $22.8(5.8)$ & $21.1(5.3)$ & $24.4(6.3)$ & 0.01 \\
\hline \multicolumn{5}{|l|}{ Ever treated for substance use } \\
\hline Yes & $62(74.7)$ & $29(76.3)$ & $33(73.3)$ & \multirow[t]{3}{*}{0.42} \\
\hline No & $19(22.9)$ & $9(23.7)$ & $10(22.2)$ & \\
\hline No response & $2(2.4)$ & $0(0)$ & $2(4.4)$ & \\
\hline Ever in prison & $43(51.8)$ & $21(55.3)$ & $22(48.9)$ & 0.43 \\
\hline HIV positive ${ }^{c}$ & $5(6.0)$ & $2(5.2)$ & $3(6.6)$ & 0.59 \\
\hline HCV positive ${ }^{c}$ & $50(60.2)$ & $22(57.9)$ & $28(62.2)$ & 0.59 \\
\hline
\end{tabular}

${ }^{\mathrm{a}}$ One client refused to answer

${ }^{b}$ Heroine use includes injection, eating, sniffing, or smoking heroin

${ }^{c} \mathrm{HIV}$ and HCV testing were conducted by MdM during completion of the baseline questionnaire

dProportion presented in this table may not add to $100 \%$ due to rounding

the program. Descriptive statistics summarized sociodemographic characteristics, health status, heroin use, and injecting characteristics. Attrition analysis was conducted to compare participant characteristics of those who remained enrolled in the program and those lost to follow-up. Statistical comparisons were made using chi-square tests for binary and categorical data and independent $t$-tests for continuous variables. STATA version 12 (College Station, TX 2012) was used for statistical analyses. 
Table 2 Distribution of characteristics among participants at baseline and endline evaluation of an OSTPP, in Kabul, Afghanistan

\begin{tabular}{llll}
\hline Characteristics & $\begin{array}{l}\text { Baseline participants }(N=83) \\
n(\%)\end{array}$ & $\begin{array}{l}\text { Endline participants }(N=57) \\
n(\%)\end{array}$ & $3.0(3.7)$ \\
\hline Mental health symptom median (SD) & $6(24.1)$ & $8.0(1.7)$ & $<0.001$ \\
General health symptom median (SD) & $5.0(2.1)$ & $35(61.4)^{\mathrm{a}}$ & $<0.001$ \\
Current heroin use (any type) & $83(100)$ & $43(75.4)$ & $<0.001$ \\
Correct HIV knowledge & $50(60.2)$ & $48(84.2)$ & 0.07 \\
Has source of income & $17(20.5)$ & $0(0)$ & $<0.001$ \\
History of criminal activity & $51(61.5)$ & $41(71.9)$ & $<0.001$ \\
Any family contact & $21(25.3)$ & $<.001$ & \\
\hline
\end{tabular}

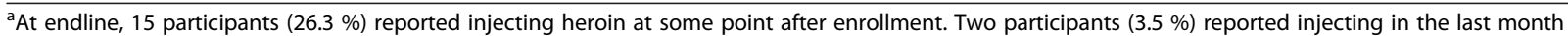

${ }^{b}$ All six characteristics presented in column one reflect the characteristic reported before enrollment vs. characteristic reported after enrollment

\section{Findings}

Overall, between February 2010 and May 2012, 95 participants were enrolled in the OSTPP. The initial number of program participants was restricted by NACP and the Ministry of Counter Narcotics to 71 participants, who were enrolled between February and September 2010. An additional 12 participants were enrolled between October 2011 and Nov 2011, totaling 83 participants with a baseline evaluation. An additional 12 participants were enrolled between November 2011 and May 2012, resulting in a total of 57 clients who were surveyed at endline by JHU (Fig. 1). All participants were male and with a mean age of 32.2 years $(\mathrm{SD}=7.8)$ at baseline. The mean daily methadone dose was of $131 \mathrm{mg} /$ day to all participants (range $=30-270 \mathrm{mg} /$ day). Of the 83 clients who were initially enrolled and surveyed by MdM, 38 clients were lost to follow-up (45.7\%) and 45 clients were retained (54.2) and at 18 months (Table 1).

Reasons for loss to follow-up included voluntary withdrawal $(n=9,20 \%)$, imprisonment $(n=8,17.8 \%)$, death ( $n=5,11.1 \%)$, migration $(n=3,6.7 \%)$, and other causes ( $n=20,44.4 \%)$. Relative to those lost to follow-up, participants who remained enrolled were more likely to be older $(p=0.01)$, single $(p<0.01)$, report daily family contact in the past month $(p<0.01)$, older age at first heroin use $(p=0.01)$, and fewer number of psychotic symptoms $(p<0.01)$ (Tables 1 and 2).

Relative to baseline participants, endline participants had better mental health $(p<0.001)$ and general health scores $(p<0.001)$, reported less heroin use $(p<0.001)$, less criminal activity $(p<0.001)$, improved family contact $(p<0.001)$, and a source of income $(p<0.001)$ (see Table 2).

\section{Discussion}

This is the first report on the retention, characteristics, and behaviors of participants in the only OSTPP in Kabul, Afghanistan. Results suggest that even under challenging circumstances, participants who remained active in the OSTPP reported improved general and mental health status, decreased heroin use and criminal activity, and improved family contact.

Program retention was relatively high (over $50 \%$ ) and comparable to programs in high-income countries, despite severe disruptions in methadone provision derived from a non-functioning importation policy during the OSTPP implementation [11]. This disruption occurred between April and May 2011 and has been associated with the death of 4 clients $[4,12]$. This suggests that even in conditions of substantial challenges, including restricted clinic working hours, required daily treatment visits, methadone stock-outs, and general instability and physical danger in Kabul, scale-up of methadone-based OST may be feasible in Kabul and could promote a positive change in specific behaviors and characteristics of participants on treatment.

Several baseline factors associated with loss to followup and retention were identified. Age at enrollment was related to retention; participants lost to follow-up were younger than those who remained enrolled. Loss of young participants is a critical barrier to overcome: young people are more vulnerable to initiation of substance use and most new HIV infections are reported among those 18-30 years old [13]. Understanding the needs and social situation of young people will facilitate OST development and implementation across this age group and may mitigate their risk of HIV and $\mathrm{HCV}$ infection [9].

Retention in the OSTPP was more likely among those with more family contact, suggesting that participants may benefit from family engagement in a treatment program [14]. Contrary to expectations, single participants at baseline were more likely to continue in the program, which may reflect having fewer social and economic needs than married participants and, thus, having more freedom to attend the clinic on a daily basis. The provision of take-home methadone, which has shown promise in other OST programs may help improve program retention by addressing the needs of participants who are married or employed [15-18]. 
The majority of participants retained in OSTPP reported reductions in heroin use, which is comparable to estimates reported in other countries [19]. By stopping heroin use, reductions in needle sharing and injecting frequency are expected, translating into fewer opportunities for HIV and HCV transmission and acquisition [20, 21], as well as other social benefits such as decreased criminal activity [22]. However, for those who continue to use heroin but at a lower rate, the effect of OSTPP on HIV and $\mathrm{HCV}$ infection might be marginal given the limited options and access to other harm reduction services $[4,23]$.

Findings should be viewed in light of several limitations. Due to restrictions on the number of enrolled participants, the overall evaluation's sample size was small. Almost half of the baseline participants were lost to follow-up, decreasing the study's power and directly affecting the generalizability and our capacity to make inferences. Participants in this study tended to be older, single, report ever being in prison, and report lower levels of employment than the wider population of injecting drug users in Kabul, thus further limiting the generalizability of our findings to the wider population of PWID in the city [1]. Interpretation of the results that compare the 83 baseline participants to the 57 endline participants must consider the fact that 12 participants did not provide baseline data. This may limit our capacity to accurately understand the factors associated with retention and OST outcomes. The OSTPP assessment was carried out within an existing program, lacking a control group and randomization. Baseline and endline data analysis reflect group changes and not individual change. Another potential bias was social desirability bias that is inherent in all socio-behavioral studies, particularly those that address illegal behaviors. The mental health questions used as part of the evaluation have not been validated for use among PWID. Future research should include validated mental health assessments that can better characterize the mental health problems of PWID. Reasons for recidivism should be identified with the aim of improving the program's performance in maintaining heroin cessation. Finally, we have no information on participants' participation in ancillary services. This information would inform on the impact of these services on participants' retention.

\section{Conclusion}

Despite limitations, findings suggest that OST in Afghanistan may be feasible in Kabul and could have positive impacts on participant behavior, supporting recommendations for use in other urban centers, such as Herat, where opioid use is prevalent [1]. This study provides preliminary data for future research and trials of optimal treatment and harm reduction programs for this setting.

\section{Abbreviations}

HCV: hepatitis C Virus; MdM: Medecins du Monde; MoPH: Afghan Ministry of Public Health; NACP: Afghan National AIDS Control Program; OST: opioid substitution therapy; OSTPP: Opioid Substitution Therapy Pilot Program; PTSD: post-traumatic stress disorder.

\section{Competing interests}

Dr. Feda Paikan served as Director of the National AIDS Control Program during the OSTPP implementation and evaluation.

\section{Authors' contributions}

All authors have contributed to, reviewed, and approved the final manuscript. HRE and IFL conducted the data analysis. HRE, AW, AV, MB, IFL, and GB drafted the manuscript. AF, EW, ST, and CE contributed with data interpretation and data collection. FP contributed to the development of the data collection plan. All authors contributed with the literature review and approved the final version of the report.

\section{Acknowledgements}

The authors acknowledged the clients of the OSTPP, Medecins du Monde, Dr. Ajmal Sabawoon, Dr. Mobeen Bromand, Dr. Khalid Ikram, Dr. Bareq Sadiq, Jessica Kali, Dr. Chris Beyrer, Dr. Andrea Ruff, Dr. Carl Latkin, Dr. Isabel Rodriguez and Dr. Homayonn Farzadegan for contributing in the study.

\section{Author details}

'Department of Psychiatry, Michigan State University, College of Ostheopathic Medicine, 965 E Fee Hall Suite A227, Lansing, MI 48824, USA. ${ }^{2}$ Department of International Health, Johns Hopkins Bloomberg School of Public Health, 615 N Wolfe Street, Baltimore, MD 21205, USA. ${ }^{3}$ Department of Emergency Medicine, Johns Hopkins University, School of Medicine, 5801 Smith Avenue, Suite 3220, Baltimore, MD 21205, USA. ${ }^{4}$ Department of Epidemiology, Johns Hopkins Bloomberg School of Public Health, Center for Public Health and Human Rights, 615 N Wolfe Street, Baltimore, MD 21205, USA. ${ }^{5}$ Department of Epidemiology, Johns Hopkins Bloomberg School of Public Health, 615 N Wolfe Street, Baltimore, MD 21205, USA. ${ }^{6}$ Medecins du Monde, Kabul, Afghanistan. ${ }^{7}$ Medecins du Monde, 63 rue de Marcadet, Paris 75018, France. ${ }^{8}$ National AIDS Control Program, Kabul, Afghanistan. ${ }^{9}$ Department of Interprofessional Health Studies, Towson University, Baltimore, MD 21252, USA.

Received: 18 July 2015 Accepted: 23 August 2015

Published online: 04 September 2015

\section{References}

1. Johns Hopkins University Bloomberg School of Public Health, Afghan National AIDS Control Program, Afghan Ministry of Public Health. Integrated Biological and Behavioral Survey 2009 (IBBS), Afghanistan. In: vol. One. Kabul, Afghanistan. 2010.

2. United Nations Office on Drugs and Crime. World Drug Report 2013. Geneva, Switzerland: World Health Organization; 2013.

3. Beyrer C, Wirtz AL, Baral S, Peryskina A, Sifakis F. Epidemiologic links between drug use and HIV epidemics: an international perspective. JAIDS. 2010:55:S10.

4. Todd CS, Macdonald D, Khoshnood K, Mansoor GF, Eggerman M, PanterBrick C. Opiate use, treatment, and harm reduction in Afghanistan: recent changes and future directions. Int J Drug Policy. 2012;23(5):341-5.

5. Des Jarlais DC, Boltaev A, Feelemyer J, Bramson H, Arasteh K, Phillips BW, et al. Gender disparities in HIV infection among persons who inject drugs in central Asia: a systematic review and meta-analysis. Drug Alcohol Depend. 2013;Suppl 1:S7-12.

6. Todd CS, Abed AM, Strathdee SA, Scott PT, Botros BA, Safi N, et al. HIV, hepatitis $C$, and hepatitis $B$ infections and associated risk behavior in injection drug users, Kabul. Afghanistan Emerging Infect Dis. 2007;13(9):1327-31.

7. Adlaf EM, Begin P, Sawka E. Canadian Addiction Survey (CAS): a national survey of Canadians' use of alcohol and other drugs: prevalence of use and related harms: Detailed report. Canadian Centre on Substance Abuse: Ottawa; 2005.

8. World Health Organization. WHO, UNODC, UNAIDS technical guide for countries to set targets for universal access to HIV prevention, treatment and care for injecting drug users-2012 revision. 2012. 
9. Degenhardt L, Mathers B, Vickerman P, Rhodes T, Latkin C, Hickman M. Prevention of HIV infection for people who inject drugs: why individual, structural, and combination approaches are needed. Lancet. 2010;376(9737):285-301.

10. MacArthur GJ, Minozzi S, Martin N, Vickerman P, Deren S, Bruneau J, et al Opiate substitution treatment and HIV transmission in people who inject drugs: systematic review and meta-analysis. BMJ. 2012;345.

11. Ball JC, Ross A. The effectiveness of methadone maintenance treatment: patients, programs, services, and outcome, Springer Science \& Business Media. 2012.

12. Razaghi E. Evaluation of Afghanistan OST pilot project: final report. In: Eastern Mediterranean Regional Office: World Health Organization. 2011.

13. Bautista CT, Todd CS, Abed AM, Botros BA, Strathdee SA, Earhart KC, et al. Effects of duration of injection drug use and age at first injection on HCV among IDU in Kabul, Afghanistan. J Public Health (Oxf). 2010;32(3):336-41.

14. Lin C, Wu Z, Detels R. Family support, quality of life and concurrent substance use among methadone maintenance therapy clients in China. Public Health. 2011;125(5):269-74.

15. Walley AY, Cheng DM, Pierce CE, Chen C, Filippell T, Samet JH, et al. Methadone dose, take home status, and hospital admission among methadone maintenance patients. J Addiction Med. 2012;6(3):186-90.

16. Peles E, Schreiber S, Sason A, Adelson M. Earning "take-home" privileges and long-term outcome in a methadone maintenance treatment program J Addiction Med. 2011;5(2):92-8.

17. Guo S, Winslow M, Manning $V$, Thane KK. Monthly take-home methadone maintenance regime for elderly opium-dependent users in Singapore. Ann Acad Med Singap. 2010;39(6):429-34.

18. Drame FM, Peitzmeier S, Lopes M, Ndaw M, Sow A, Diouf D, et al. Gay men and other men who have sex with men in West Africa: evidence from the field. Cult Health Sex. 2013;15(Suppl):7-21.

19. Amato L, Davoli MA, Perucci C, Ferri M, Faggiano FP, Mattick R. An overview of systematic reviews of the effectiveness of opiate maintenance therapies: available evidence to inform clinical practice and research. J Subst Abus Treat. 2005;28(4):321-9

20. Gowing L, Farrell M, Bornemann R, Ali R. Substitution treatment of injecting opioid users for prevention of HIV infection. Cochrane Library. 2004:10:CD004145.

21. Tilson H, Aramrattana A, Bozzette S, Celentano D, Falco M, Hammett T, et al. Preventing HIV infection among injecting drug users in high-risk countries: an assessment of the evidence. Washington, DC: Institute of Medicine; 2007.

22. Gossop M, Marsden J, Stewart D, Treacy S. Outcomes after methadone maintenance and methadone reduction treatments: two-year follow-up results from the National Treatment Outcome Research Study. Drug Alcohol Depend. 2001;62(3):255-64.

23. Strathdee SA, Hallett TB, Bobrova N, Rhodes T, Booth R, Abdool R, et al. HIV and risk environment for injecting drug users: the past, present, and future. Lancet. 2010;376(9737):268-84.

\section{Submit your next manuscript to BioMed Central and take full advantage of:}

- Convenient online submission

- Thorough peer review

- No space constraints or color figure charges

- Immediate publication on acceptance

- Inclusion in PubMed, CAS, Scopus and Google Scholar

- Research which is freely available for redistribution

Submit your manuscript at www.biomedcentral.com/submit 